\title{
Multiple Nodular Swelling in Both Upper and Lower Limbs
}

\author{
A DAS $^{\mathrm{a}}$, M PARVIN ${ }^{\mathrm{b}}$, MA KAHHAR
}

(J Banagladesh Coll Phys Surg 2014; 32: 53-54)

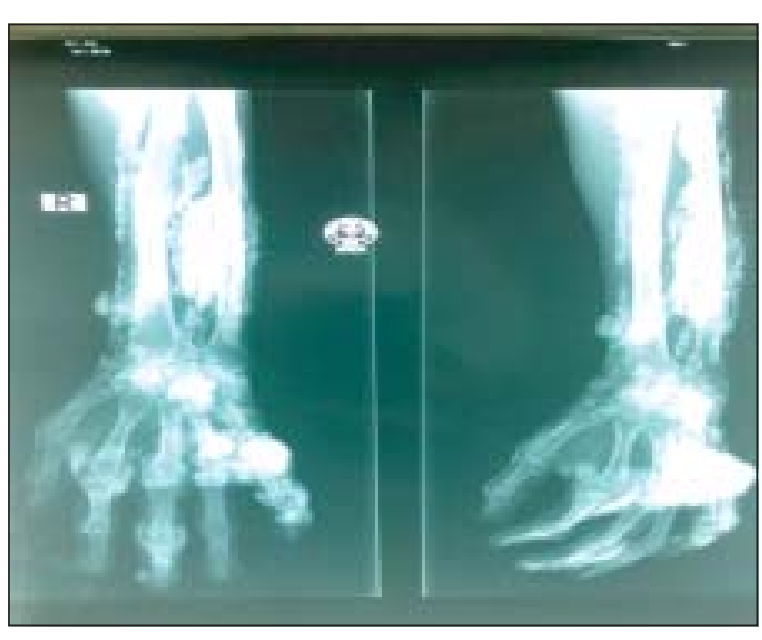

Fig.-1: Showing Soft tissue calcification involving the forearm and hand

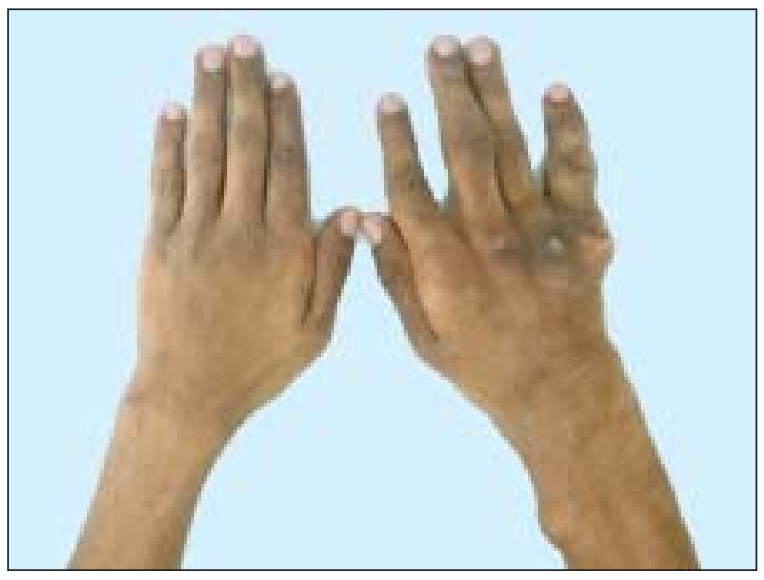

Fig.-2: Showing nodular swelling with chocky surface in hand and forearm

1. Dr. Aparna Das. Asso. Prof. Dept of Medicine, Dhaka Medical College

2. Dr. Mania Parvin, Dept of Medicine, Dhaka Medical College

3. Prof. Md. Azizul Kahhar, Professor, Dept of Medicine, Dhaka Medical College

Address of Correspondence: Dr. Aparna Das. Asso. Prof. Dept of Medicine, Dhaka Medical college.M:01914978719

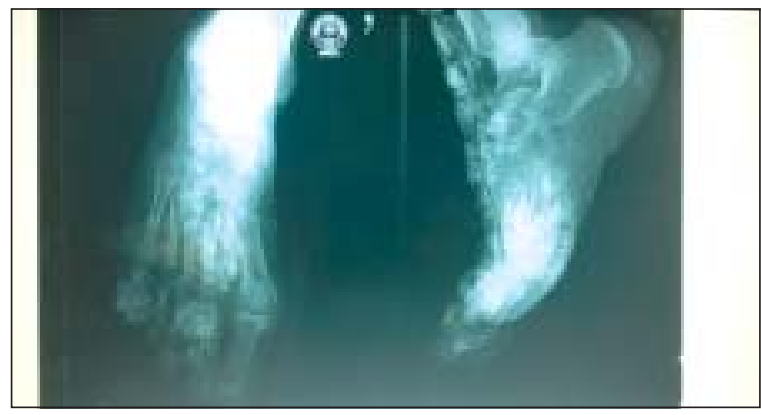

Fig.-3: Showing Soft tissue calcification involving the foot

A 17 year- old- boy presented with multiple nodular swelling in right upper limb and feet for 2 years ,and proximal muscle weakness for 2 months. Two years ago patient notice a small nodular swelling over wrist, which was farm later become hard, with the passge of time he develop multiple nodular swelling without any limitation of daily activities. For last 2 month he develop difficulty in standing from sitting position. Such types of illness didn't run in his family, patient have not histry of taking myopathic drugs. General examination reveals multiple nodular swelling involving ulnar surface of right forearm, $2^{\text {nd }} \& 5$ thmetacarpophalangeal joint ,wrist ,right foot, which are nontender, most of them are hard with few firm in consistency, fixed with underlying structure but free from overlying skin without discharging sinus, largest one is $(2,2 \mathrm{~cm})$. On CNS examination only muscle power of proximal group of lower limb $4 / 5$,feature of proximal myopathy. Investigation shows $\mathrm{Hb} 11.2 \mathrm{~g} / \mathrm{dl}$, ESR $15 \mathrm{~mm}$ (1stHr), TC 15,000., CPK : 2881 U/L, S. Creatinine, RBS , S.uric acid, S.calcium, S.albumin,Thyroid function test, S. electrolytes and Urine R/M/E are normal. CRP is negative, SGPT : $110 \mathrm{U} / \mathrm{L}$, SGOT : $223 \mathrm{U} / \mathrm{L}$. ANA and Anti-Centromere $\mathrm{Ab}$ are negative. Muscle biopsy features consistent with dermatomyositis. Prednisolone $40 \mathrm{mg}$ was administered daily with symptomatic improvement. In a recent follow up patient muscle weakness was improved but no exacerbation or resolution of calcinosis was observed. 


\section{Discussion:}

When calcification is processed any tissue other than bone and teeth is termed calcinosis and can occur in many condition including connective tissue disease, hyper-parathyroidism, renal failure and vitamin D intoxication $^{1}$. Calcinosis may devided into four categories according to the pathogenesis as follows; dystrophic, metastatic, diopathic and iatrogenic. In connective tissue disease, calcinosis is mostly of dystrophic type and it seems to be localized process rather than an imbalance of calcium homeostasis. Calcinosis in connective tissue disease about $9 \%$ patient with seleroderma ${ }^{2,3}$ and $5 \%$ to $20 \%$ of adult ${ }^{4}$ and $40 \%$ to $74 \%$ of children with dermatomyositis. The existence of calcinosis is indicative of a good prognostic sign of survival but may also be incapacitating.

Dermatomyositis is an idiopathic inflammatory myopathy with characteristic cutaneous manifestation, including helitroperash, gottronpapules, periungual telangiectasias, photo distribution erythema, poikiloderma and alopecia. Although helitrope rash and gottron papules are specific feature, calcinosis may occur upto $40 \%$ of children or adolescent.

The laboratory hallmark are elevated creatine kinase, aldolase and transaminase, and a characteristic pattern of EMG-spotty muscle necrosis, regeneration, and inflammation are the pathological hallmark. Calcinosis can be a disability complication that may affect the skin,subcutaneous tissue. It occur most during the course of juvenile dermatomyositis ${ }^{3}$. Calcinosis usually occurred two or three year after onset of dermatomyositis, after that the deposition remain stable and spontaneous resolution has been occasionally reported ${ }^{5}$. The cause and mechanism of calcification are unknown. calcium deposition are ofen in those muscle that were most severly affected during acute phase of disease. Serum calcium, phosphate and urinary calcium values are within the normal range ${ }^{2}$. The calcinosis can be demonstrable both clinically and radiologically. A whole body scan with 99m TC pyrophosphate and CT scan can also identify calcinosis $^{6}$. Aggresive treatment with high doses of prednisolone and physical therapy can decrease the incidence of calcinosis ${ }^{5}$. The use of bisphosphonate in the treatment of soft tissue calcification has varing result $^{7,8}$.Two studies shows suppression of GIa synthasis by warfarin sodium may prevent deposition and allow for removal of existing calcinosis. Large and localized mass may be remove surgically 9,10 .

\section{Conclusion:}

Calcinosis is often signals a improved prognosis. Spontaneous regression of calcification was reported upto $50 \%$ of the cases.

\section{References:}

1. Mullar SA, Winkleman RK, Brunsting LA. Calcionosis in dermatomyositis: Observation on course of diesaes in children and adults. Arch Dermatol 1959; 79: 669-73

2. Bowyer SL, Blane CE, Sullivan DB, Cassidy JT. Childhood dermatomyositis: Factors predicting functional outcome and development of distrophic calcification. J Pediatr 1983; 103: 882-8.

3. Randle HW,Sander HM,Howward K,Early diagnosis of Calcionosis cutis in Childhood using CT.JAMA 1986;256;1137-8.

4. Mullar SA, Winkleman RK, Brunsting LA. Calcionosis cutis: Its relationship to scleroderma. Arch Dermatol 1959; 80: 1521

5. Blane CE,White SJ,Braunstein EM, Blane CE.Pattern of calcification in Childhood dermatomyositis.AJR 1984;142;397-400

6. GehoWB,White JA.Clinicaal aspect of metabolic bone disease,Amsterdam;excerpta Medical,1973;506-12.

7. Uttley WS,Belton NR,Syme J.Calcium balance in children treated with diphosphonates.Arch Dis Child 1975;50; 187-90.

8. Carlason M,lindseth RE,DeRoss.Surgical removal of soft tissue calcification in dermatomyositis.Arch surg 1975;110;755-6.

9. SheArin JC,Pickrell K.Surgical treatment of dermatomyositis.Ann Plast Surg 1980;5;381-2.

10. Ostrovo BE,Goldsmith DP,Eichenfild AH,Athreya BH.Hypercalcemia during resolution of calcinosis universalis in juvenile dermatomyositis.BMJ 1984;288;1345 